\title{
Tc and Re Behavior in Borosilicate Waste Glass Vapor Hydration Tests
}

\author{
David A. McKeown ${ }^{*}$, Andrew C. Buechele, Wayne W. Lukens ${ }^{+}$, David K. Shuh ${ }^{+}$, and Ian
} L. Pegg

Vitreous State Laboratory

The Catholic University of America

620 Michigan Ave, N.E., Washington, D.C. 20064

USA

${ }^{+}$Actinide Chemistry Group

Chemical Sciences Division

Lawrence Berkeley National Laboratory

Berkeley, CA 94720

USA

* corresponding author: davidm@vsl.cua.edu, Phone: (202) 319-5226, FAX: (202) 319-

4469

\begin{abstract}
Technetium (Tc), found in nuclear waste, is of particular concern with regard to longterm waste storage because of its long half-life and high mobility in the environment. One method of stabilization of such waste is through vitrification to produce a durable borosilicate glass matrix. The fate of Tc under hydrothermal conditions in the Vapor Hydration Test (VHT) was studied to assess and possibly predict the long-term rate of release of Tc from borosilicate waste glass. For comparison, the fate of rhenium (Re), the preferred non-radioactive surrogate for Tc, was similarly studied. X-ray absorption spectroscopy (XAS) and scanning electron microscopy (SEM) measurements were made on each original borosilicate glass and the corresponding sample after the VHT. Tc K-
\end{abstract}


edge XAS indicates that, despite starting with different $\mathrm{Tc}(\mathrm{IV})$ and $\mathrm{Tc}(\mathrm{VII})$ distributions in each glass, both corresponding VHT samples contain 100\% Tc(IV). The Tc reduction within the VHT samples may be driven by simultaneous oxygen depletion from corrosion of the surrounding stainless steel vessel. From SEM analyses, both of the Tc-containing VHT samples show complete alteration of the original glass, significant Tc enrichment near the sample surface, and nearly complete depletion of Tc toward the sample center. XAS indicates $\mathrm{Tc}(\mathrm{IV}) \mathrm{O}_{6}$ octahedra, possibly within gel-like amorphous silicates in both VHT samples, where Tc-Tc correlations are observed in the higher Tc-content VHT sample. Re $\mathrm{L}_{\mathrm{II}}$-edge XAS and SEM indicate quite different behavior for Re under VHT conditions. Re oxidation state appears to be invariant with respect to the VHT treatment, where perrhenate $(\operatorname{Re}(\mathrm{VII}))$ species are dominant in all Re-containing samples investigated; $\mathrm{Re}_{2} \mathrm{O}_{7}$ concentrations are low NEAR the sample surface and increase to approach the concentration of the un-reacted glass toward the sample center. 


\section{MANUSCRIPT TEXT}

\section{Introduction}

One of the most difficult problems associated with the use of nuclear power and the disposition of nuclear wastes from fuel reprocessing is the long-term immobilization of the radionuclides produced during fission, such as technetium $\left({ }^{99} \mathrm{Tc}\right)$. Tc is a $\beta$-emitter with a half-life of $2.13 \times 10^{5}$ years. The thermodynamically stable form of Tc in aerobic environments is highly mobile pertechnetate ( $\mathrm{Tc}(\mathrm{VII})$ within $\mathrm{TcO}_{4}{ }^{-}$tetrahedra) $(1,2)$. The long half-life and high mobility of pertechnetate frequently make it one of the most significant environmental risk contributors in the performance assessment of nuclear waste disposal repositories. Currently, the chosen method of treatment for the most highly radioactive nuclear wastes is vitrification to produce a durable glass matrix. It is known from the geologic record that natural glasses of appropriate compositions have survived for millions of years in the environment (3). Projection of the fate of waste glasses in the environment, which necessarily have somewhat different compositions from natural glasses, requires an understanding of the processes and mechanisms by which they alter on exposure to the prevailing environmental conditions; reaction with water is crucial in this regard. Since the preferred glass compositions have inherently low rates of alteration, a variety of accelerated test methods have been developed wherein other test variables (such as temperature or surface area to volume ratio) are employed to bring about a greater extent of reaction in a shorter time. Such tests have proved useful in elucidating reaction mechanisms and in the down-selection of glass compositions. One such test method, which is the subject of this study, is the Vapor Hydration Test (VHT).

The VHT employs hydrothermal conditions to accelerate the rate of glass alteration. In the VHT, a glass coupon is exposed to a water-saturated atmosphere in a sealed pressure bomb at elevated temperatures for specified time intervals. At the end of the test, the coupon is sectioned and analyzed to determine the thickness of the reacted layer, which gives a measure of the rate of reaction, and the types and compositions of the alteration phases that are produced $(4-8)$. Previous work has shown that water diffuses 
into the glass ahead of the alteration zone (7) and that alteration phases can develop either in place of the native glass or growing out from the coupon surface $(4-8)$. However, to the best of our knowledge, Tc behavior is unknown with regard to mobility and speciation within a borosilicate waste-form under VHT conditions. In view of the practical importance of rhenium, which is commonly used as a non-radioactive surrogate for Tc, tests were also performed on two Re-containing waste glasses to allow comparisons with the behavior of Tc.

The speciation and local coordination environments of $\mathrm{Tc}$ and Re, in the original glasses and the corresponding VHT samples, were determined using X-ray absorption spectroscopy (XAS). As shown earlier (9-12), XAS can distinguish $\mathrm{Tc}(\mathrm{IV}) \mathrm{O}_{6}$ octahedra from $\mathrm{Tc}(\mathrm{VII}) \mathrm{O}_{4}$ tetrahedra in borosilicate waste glasses and other materials. Tc K-edge X-ray absorption near edge structure (XANES) for Tc(IV) and Tc(VII) are distinctive (910,12). The structural parameters extracted from the extended X-ray absorption fine structure (EXAFS) data can also be used to distinguish pertechnetate tetrahedra, which have Tc-O distances near $1.72 \AA$, from Tc(IV) octahedra, which have Tc-O distances near $1.98 \AA$ A. Recent studies (9) have also shown that Re $\mathrm{L}_{\text {II }}$ XANES data can be used to distinguish $\mathrm{Re}(\mathrm{VII})$ from more reduced species in borosilicate waste glasses.

\section{Experimental Section}

Sample Preparation. Four borosilicate glasses were investigated. Two Tc-containing glasses, II-118 and II-121, were synthesized in Pt/Au crucibles in air within a tube furnace at $1150^{\circ} \mathrm{C}$; both samples contain no $\mathrm{ZrO}_{2}$ to avoid large $\mathrm{X}$-ray fluorescence background intensity in the Tc K-edge XAS data. Two Re-waste glasses, WVT-G-126B and WVT-G-128B, were produced in test runs on a continuously-fed ceramic-lined Jouleheated melter (13), where the $\sim 110 \mathrm{~kg}$ melt pool was maintained at $1150^{\circ} \mathrm{C}$ and agitated by an air bubbler. Reagent-grade chemical components were used for glass synthesis. Chemical compositions of the glasses were determined by $\mathrm{X}$-ray fluorescence spectroscopy (XRF) as well as Direct Coupled Plasma-Atomic Emission Spectroscopy (DCP-AES) analyses (Table S1). Tc concentrations in the original glasses were 
determined by liquid scintillation measurements on solutions generated by microwaveassisted $\mathrm{HNO}_{3} / \mathrm{HF}$ dissolution of the glass samples. All glasses were determined to be crystal-free by X-ray diffraction (XRD), except for a few isolated Pt inclusions in the Tccontaining glasses.

Individual wafers were cut from the two Tc-containing glasses and the two Recontaining melter glasses for the VHT experiments. Each wafer was suspended above a small amount of water in a sealed stainless steel VHT pressure bomb (Fig. S1), that was flushed with $\mathrm{Ar}$, and then held at $238^{\circ} \mathrm{C}$ for 24.9 days. At the end of the VHT, optical inspection found that the II-118 and II-121 VHT samples were reacted throughout, while the WVT-G-126B and WVT-G-128B VHT samples were 60-70\% reacted. It should be noted that the difference in the degree of alteration is due to $\mathrm{ZrO}_{2}$ content variations in these glasses (Table S1) and not the differences between Tc and Re. XRD indicates analcime $\left(\mathrm{NaAlSi}_{2} \mathrm{O}_{6} \cdot \mathrm{H}_{2} \mathrm{O}\right)$, and possibly, $\mathrm{Zn}$-silicate crystalline phases in the Tccontaining VHT altered samples. Additional sample preparation and VHT details are in the Supporting Materials.

SEM Measurements. Concentrations of Tc and Re in the original glasses and in the corroded VHT coupon cross-sections were determined by wavelength dispersive spectroscopic (WDS) analysis. All elements present at $1 \mathrm{wt} . \%$ or greater (as oxides) were analyzed to provide the basis for matrix corrections, except $\mathrm{H}, \mathrm{Li}$, and $\mathrm{O}$, with the last being evaluated by stoichiometry. The starting glasses were used as standards for all elements except Tc and Re. For Tc, a specially prepared specimen containing $\mathrm{Na}, \mathrm{Tc}, \mathrm{Si}$, and $\mathrm{O}$ was used, whereas for $\mathrm{Re}, \mathrm{ReO}_{3}$ was used.

XAS Data Collection. Tc K-edge and $\mathrm{Re} \mathrm{L}_{\mathrm{II}}$-edge XAS data were collected in fluorescence mode at Stanford Synchrotron Radiation Laboratory Beam Lines 4-1 and 11-2. Due to the relatively low Tc concentrations in the original Tc-containing glasses (Table S1), only Tc XANES data could be collected and analyzed. The X-ray 
fluorescence signal was significantly improved for both Tc-containing altered VHT wafers, such that XANES as well as EXAFS data were collected for these samples. This signal improvement for the Tc-containing VHT wafers indicates significant Tc enrichment at the VHT wafer surface compared with the Tc distribution in the original glass, a result confirmed by SEM analysis. No improvement in the XAS data was observed for the Re-containing VHT samples compared with the data for the original glasses.

\section{XAS Data Analysis}

The X-ray absorption spectra were processed using standard pre-edge background subtraction and edge-step normalization procedures (14). Each spectrum was calibrated to the inflection point of the $\mathrm{K}$-edge peak for $\mathrm{TcO}_{4}{ }^{-}$at $21,044 \mathrm{eV}$ or the $\mathrm{L}_{\mathrm{II}^{-}}$-edge spectrum of Re metal at $11,959 \mathrm{eV}$. Energy values in $\mathrm{eV}$ were converted to $\mathrm{k}\left(\AA^{-1}\right)(14)$, where after background subtraction, the resulting $\chi(\mathrm{k})$ data were $\mathrm{k}^{3}$-weighted and then Fourier transformed to produce the partial radial distribution functions (RDFs). XAS data for crystalline $\mathrm{TcO}_{2}$ and amorphous $\mathrm{TcO}_{2} \bullet \mathrm{H}_{2} \mathrm{O}\left(a-\mathrm{TcO}_{2} \bullet \mathrm{xH}_{2} \mathrm{O}\right.$, where $\left.\mathrm{x} \sim 1.6\right)$ were used for comparisons with the Tc-containing VHT sample data, and were presented $(11,12)$. Tc-O and Tc-Tc correlations determined for crystalline $\mathrm{TcO}_{2}(11)$ and $a$ $\mathrm{TcO}_{2} \bullet \mathrm{xH}_{2} \mathrm{O}$ (12) were used to label the major RDF features for these samples.

FEFF 7.02 computer code (15) was used to calculate important Tc-O and Tc-Tc correlations in crystalline $\mathrm{TcO}_{2}$. Due to the complex Tc environment in crystalline $\mathrm{TcO}_{2}$ (11), with five different Tc-O nearest-neighbor distances (ranging from 1.96 to $2.06 \AA$ ) and nine different Tc-Tc distances (ranging from 2.29 to $3.67 \AA$ ), the data for this sample was not used as the reference for EXAFS fitting. Instead, the calculated Tc-O and Tc-Tc correlations were used by the fitting program, FEFFIT (16) to fit the partial RDF for $a$ $\mathrm{TcO}_{2} \bullet \mathrm{xH}_{2} \mathrm{O}$, where the results were checked against those presented (12). FEFFIT determined $r$ (average bond distance), $n$ (coordination number), and $\sigma^{2}$ (Debye-Waller 
factor) for the major features in the partial RDFs for $a-\mathrm{TcO}_{2} \bullet \mathrm{xH}_{2} \mathrm{O}$ and the two Tccontaining VHT samples (Table 1). FEFFIT varied $r, n$, and $\sigma^{2}$ for each atomic shell, while minimizing the r-factor, a goodness of fit parameter that is a sum-of-squares measure of the fractional misfit scaled to the magnitude of the data (Table 1). Other analysis details are included in the supporting material.

\section{Results and Discussion}

\section{VHT Treated Samples: Tc-Containing Waste Glasses}

SEM Observations. SEM-WDS analyses for Tc were made at several selected points within the original glass samples, where the Tc concentrations were 0.008 and 0.004 wt.\% for II-118 and II-121 glasses, respectively (Table S1). SEM-WDS analyses of both VHT samples indicate Tc and Si occur together at the locations analyzed, which suggests that Tc is incorporated within silicates. The SEM findings indicate that it is unlikely that Tc within these samples is in $a-\mathrm{TcO}_{2} \bullet \mathrm{xH}_{2} \mathrm{O}$, unless particles, with diameters considerably less than $1 \mu \mathrm{m}$, of this phase are suspended within silicates.

SEM-WDS analyses on cross-sections of both VHT samples indicate Tc concentration variations as a function of distance from the surface (Fig. 1; Tables S2 and S3). Tc concentrations at the II-118 VHT sample surface are enhanced by approximately $50 \%$, compared with that in the original glass (Fig. 1). At depths of 25 to $125 \mu \mathrm{m}$ from the surface, Tc concentrations are similar to those in the original glass. However, beyond a depth of $150 \mu \mathrm{m}$, Tc appears to be completely depleted from the sample (statistically zero). Similar relationships are observed for Tc concentrations within the II-121 VHT sample (Table S3). Near the surface, at depths up to $150 \mu \mathrm{m}$, Tc concentrations can be five times of that measured by SEM for the original II-121 glass. Between depths of 175 and $300 \mu \mathrm{m}$, Tc concentrations within this VHT sample are similar to those found for the original II-121 glass; at depths greater than $300 \mu \mathrm{m}$, Tc concentrations approach zero. 
Tc Concentration (wt.\%)

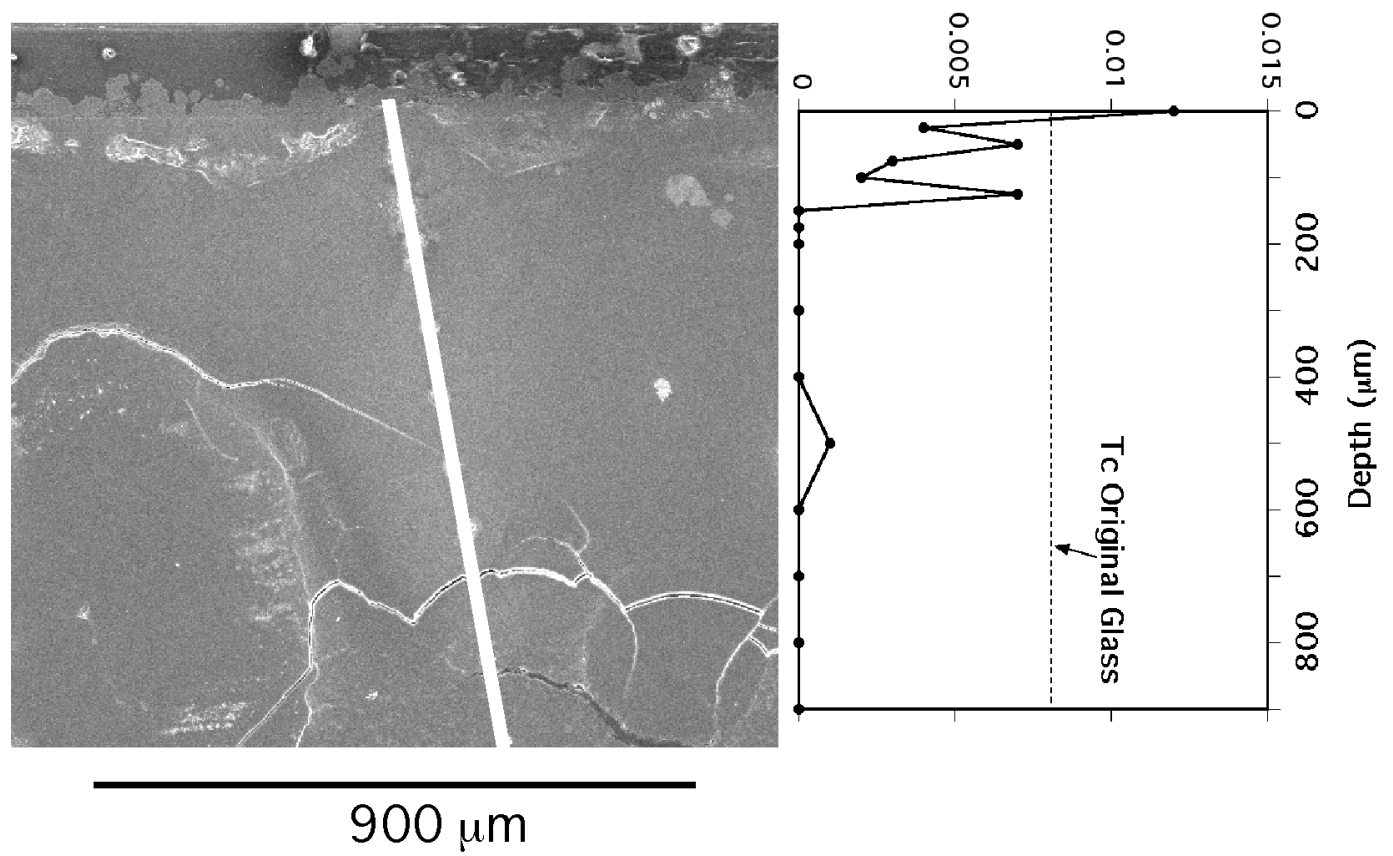

Figure 1. SEM-WDS Tc analyses for the II-118 VHT sample cross-section. The side plot indicates Tc concentration versus cross-section depth from the outer surface. The analysis profile is the white bar in the SEM micrograph.

SEM analyses for most major elements in both VHT samples indicate that concentrations remain relatively constant throughout the cross-section profiles (Tables S2 and S3). Exceptions are Na, Ca, and Fe for the II-118 VHT sample, and Ca for the II-121 VHT sample, where these elements show significant enrichment near the surface.

Both Tc-containing VHT samples were completely altered, such that none of the original glass remained. The SEM images for both samples indicate significant differences with regard to how each original glass was altered. The II-118 VHT sample shows more homogeneous alteration textures, where ill-defined bands of various phases can be seen just under the surface and near a depth of $900 \mu \mathrm{m}$ (Fig. 1). The II-121 VHT sample has a more complex assemblage of alteration phases and phase intergrowth textures throughout, with more distinct bands. 
XANES Results. Tc K-edges for the two samples show significant changes before and after the VHT (Fig. 2). XANES for the VHT samples are shifted to lower energies and show no evidence of the 21,045 eV pertechnetate edge feature (Fig. 3 bottom) compared with the XANES for II-118 and II-121 glasses. The XANES for the $100 \% \mathrm{Tc}$ (VII) standard glass (I-283) and the $100 \%$ Tc(IV) standard glass (II-13) (9) show significant edge shape differences as well as a $3.5 \mathrm{eV}$ edge energy shift (measured at half the edgestep) (Fig. 3). Fitting the XANES data for the original glasses (Fig. 2), using the spectra of the $\mathrm{Tc}(\mathrm{IV})$ and $\mathrm{Tc}(\mathrm{VII})$ glass standards, indicate $20 \% \mathrm{Tc}(\mathrm{IV})+80 \% \mathrm{Tc}(\mathrm{VII})$ for II-118 glass versus $80 \% \mathrm{Tc}(\mathrm{IV})+20 \% \mathrm{Tc}(\mathrm{VII})$ for II-121 glass (9). These changes indicate that any pertechnetate originally present in the II-118 and II-121 glasses has been reduced to $\mathrm{Tc}(\mathrm{IV})$ during VHT alteration. The data for both VHT samples are different from the spectrum for the $100 \%$ Tc(IV) II-13glass (Fig. 3). The two peaks near 21,065 and 21,075 $\mathrm{eV}$ in both VHT sample spectra are similar to those observed for crystalline $\mathrm{TcO}_{2}$ and $a$ $\mathrm{TcO}_{2} \bullet \mathrm{xH}_{2} \mathrm{O}$ (Fig. 3)(12). The double peak feature for the II-121 VHT sample is clearly more resolved than that for the II-118 VHT sample, indicating structural differences around Tc. From the XANES evidence, the Tc environments in both VHT samples appear to be similar to those in crystalline $\mathrm{TcO}_{2}$ or $a-\mathrm{TcO}_{2} \bullet \mathrm{xH}_{2} \mathrm{O}$, where $\mathrm{Tc}(\mathrm{IV}) \mathrm{O}_{6}$ units link to create Tc-Tc second-nearest neighbors. 


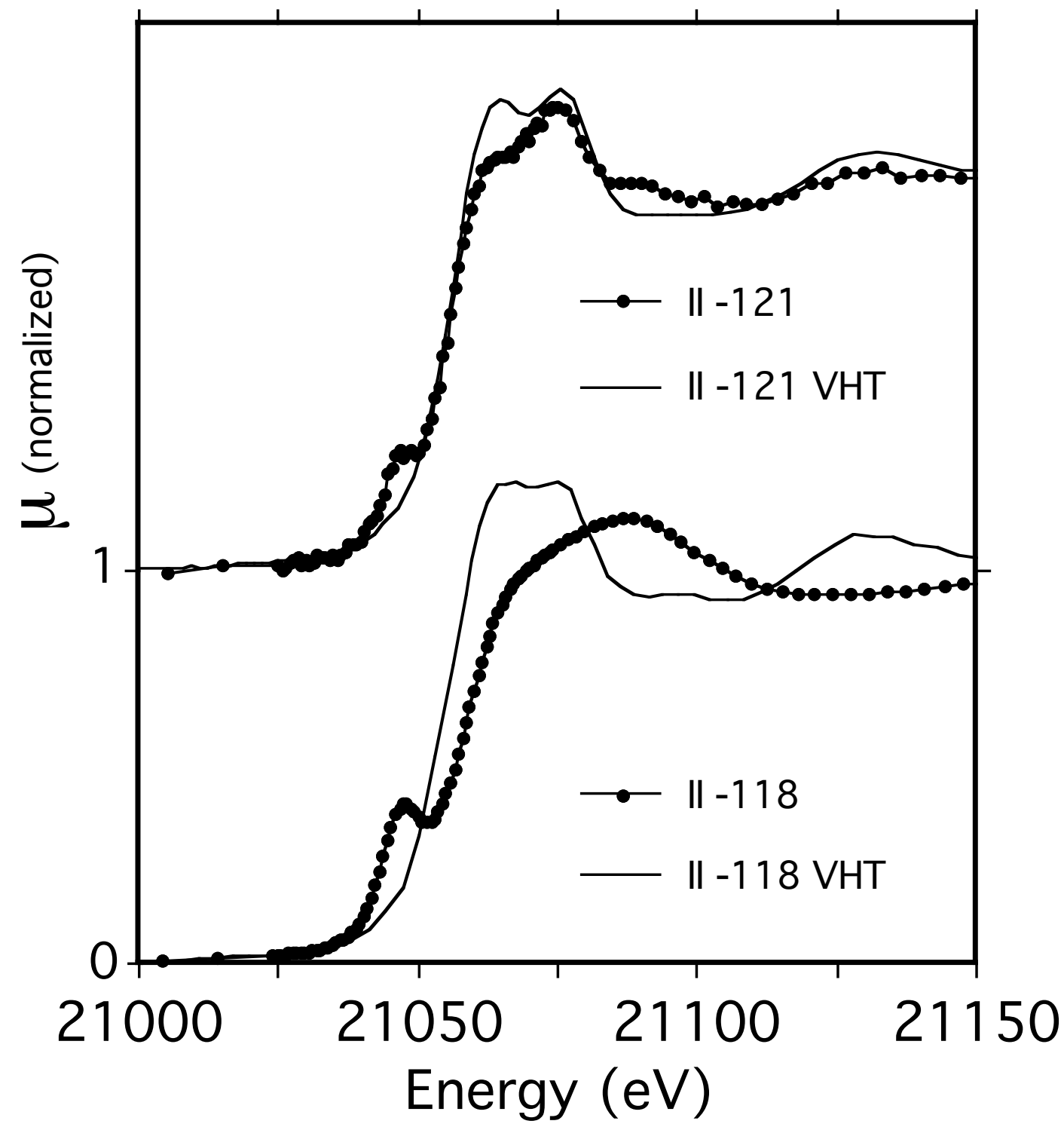

Figure 2: Tc K-edge XANES data for the II-118 and II-121 samples before and after VHT treatment. II-118 glass contains $20 \% \mathrm{Tc}(\mathrm{IV})+80 \% \mathrm{Tc}(\mathrm{VII})$ and II-121 glass contains $80 \% \mathrm{Tc}(\mathrm{IV})+20 \% \mathrm{Tc}(\mathrm{VII})(9)$. Both corresponding VHT samples have $100 \%$ Tc(IV). 


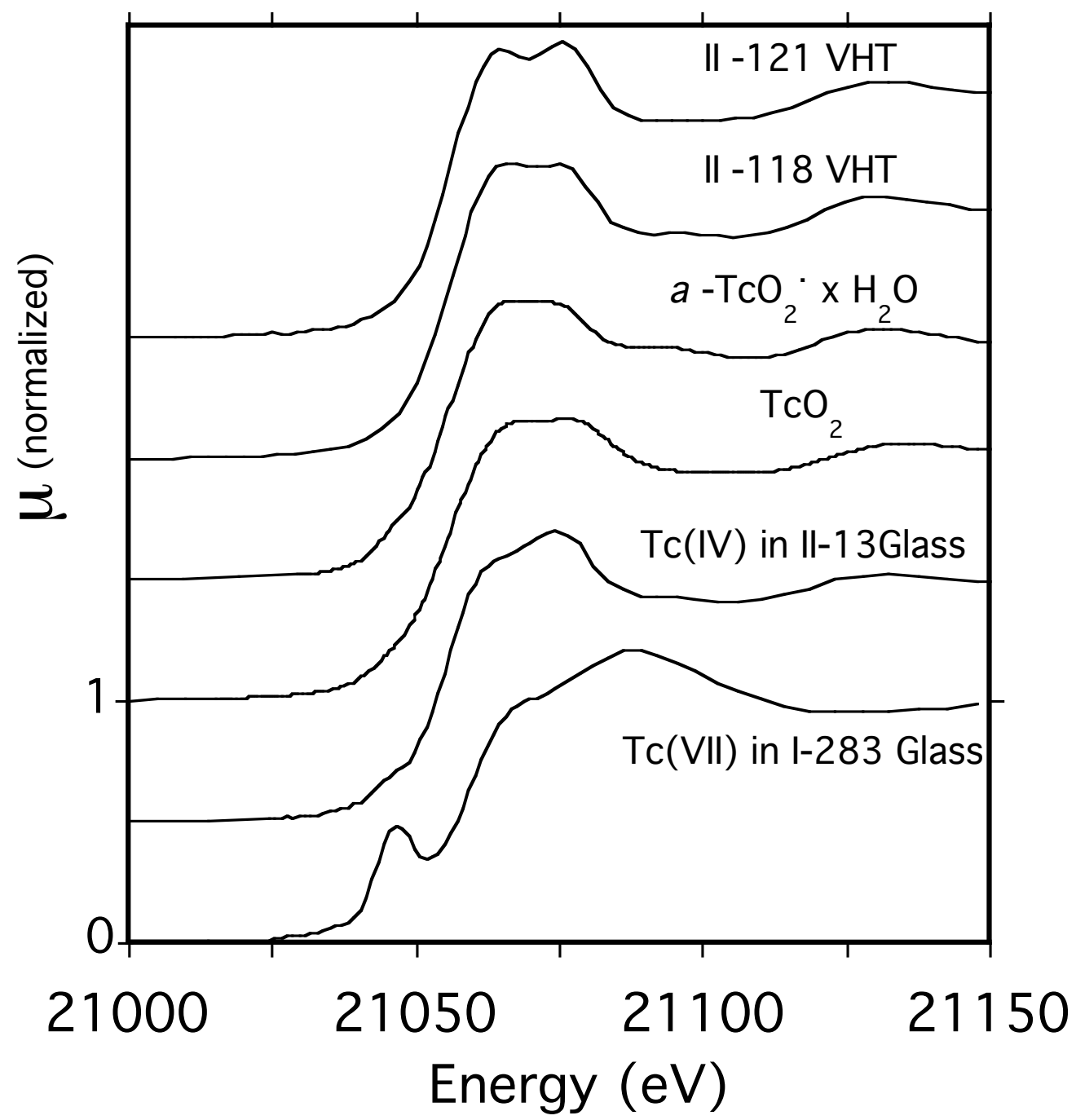

Figure 3: Tc XANES of the Tc(VII) in glass standard, crystalline and amorphous Tc(IV) standards, and the two Tc-containing VHT samples.

EXAFS Results. The $\mathrm{k}^{3} \chi(\mathrm{k})$ data for both VHT samples have larger oscillation amplitudes at k-values under $8 \AA^{-1}$ than those observed for $a-\mathrm{TcO}_{2} \bullet \mathrm{XH}_{2} \mathrm{O}$, that are similar 
to those for crystalline $\mathrm{TcO}_{2}$ (Fig. 4). At k-values greater than $8 \AA^{-1}$, the data for II-118 VHT and $a-\mathrm{TcO}_{2} \bullet \mathrm{H}_{2} \mathrm{O}$ are similar, while the data for crystalline $\mathrm{TcO}_{2}$ is different from the other three samples. The data for $a-\mathrm{TcO}_{2} \bullet \mathrm{xH}_{2} \mathrm{O}$ and the II-118 VHT sample show at least two different frequency components, whereas one dominant frequency component is observed for the II-121 VHT sample.

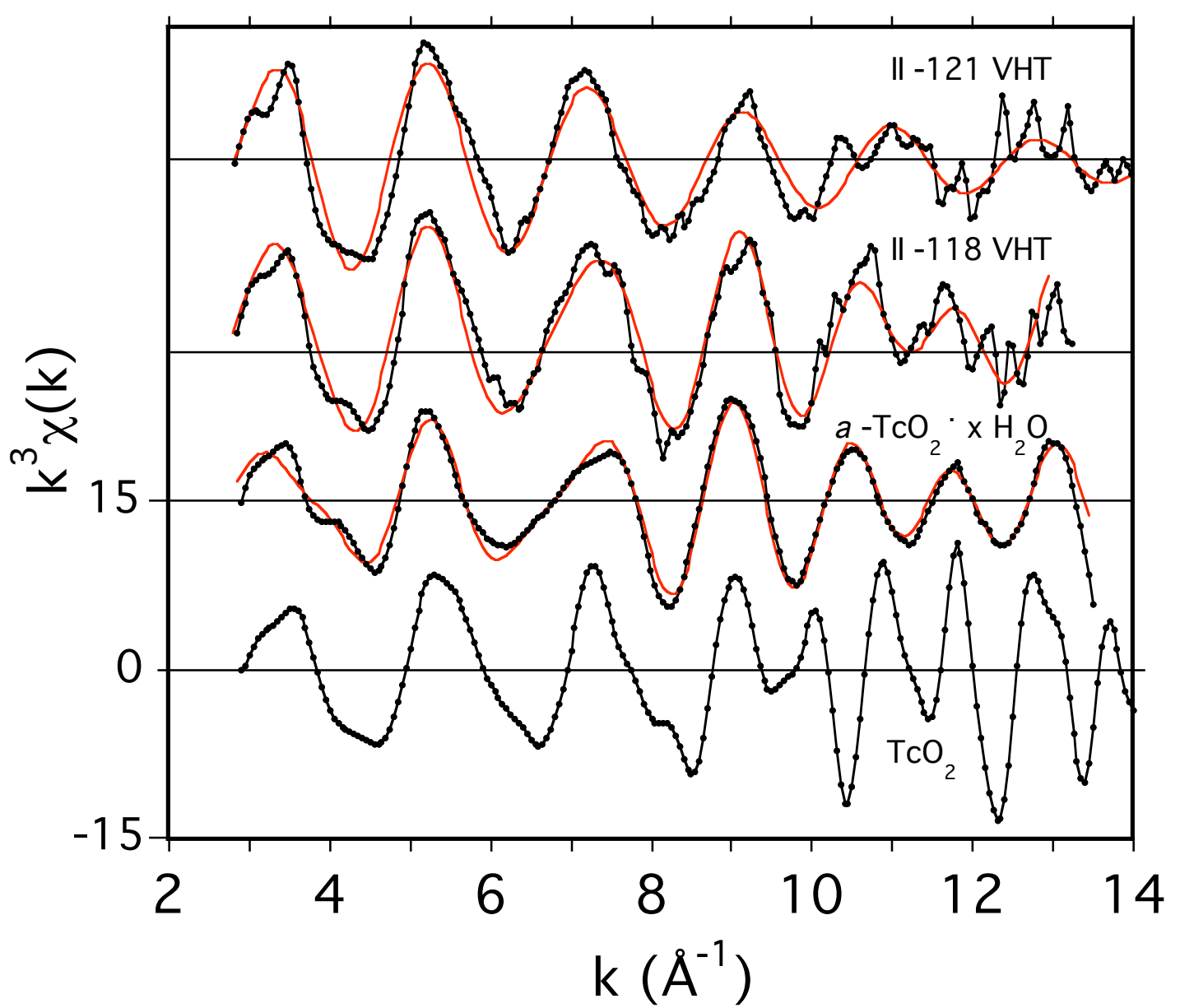

Figure 4: Tc EXAFS data (line and points) and analysis fit (red line) for crystalline $\mathrm{TcO}_{2}$, $a-\mathrm{TcO}_{2} \bullet \mathrm{xH}_{2} \mathrm{O}$ and the two Tc VHT samples.

The partial RDFs clearly indicate structural differences among the four samples (Fig. 5). The two VHT samples show similar first shell peak amplitudes to that for 
crystalline $\mathrm{TcO}_{2}$; the first shell peak amplitude for $a-\mathrm{TcO}_{2} \bullet \mathrm{xH}_{2} \mathrm{O}$ is noticeably weaker than that for the other three samples. The RDF for the II-118 VHT sample has a second shell peak near $2.4 \AA$, similar to the Tc-Tc peak for $a-\mathrm{TcO}_{2} \bullet \mathrm{xH}_{2} \mathrm{O}$. The RDF for the II121 VHT sample has a nearest-neighbor peak near 1.7 $\mathrm{A}$. The RDF for $\mathrm{TcO}_{2}$ indicates Tc-Tc correlation peaks at $r$ greater than $2 \AA$ that are distinctly different from the other three samples.

The analysis of the $a-\mathrm{TcO}_{2} \bullet \mathrm{xH}_{2} \mathrm{O}$ data reproduced results obtained for this phase (12) (Table 1). The fitting results indicate that Tc is coordinated by six oxygen atoms in a distorted octahedral arrangement: four equatorial oxygens at an average $2.01 \AA$ Tc-O distance and two apical oxygens (each associated with $\mathrm{H}_{2} \mathrm{O}$ ) at $2.49 \AA$ from Tc. Each Tc has two Tc second-nearest neighbors at $2.58 \AA$. 


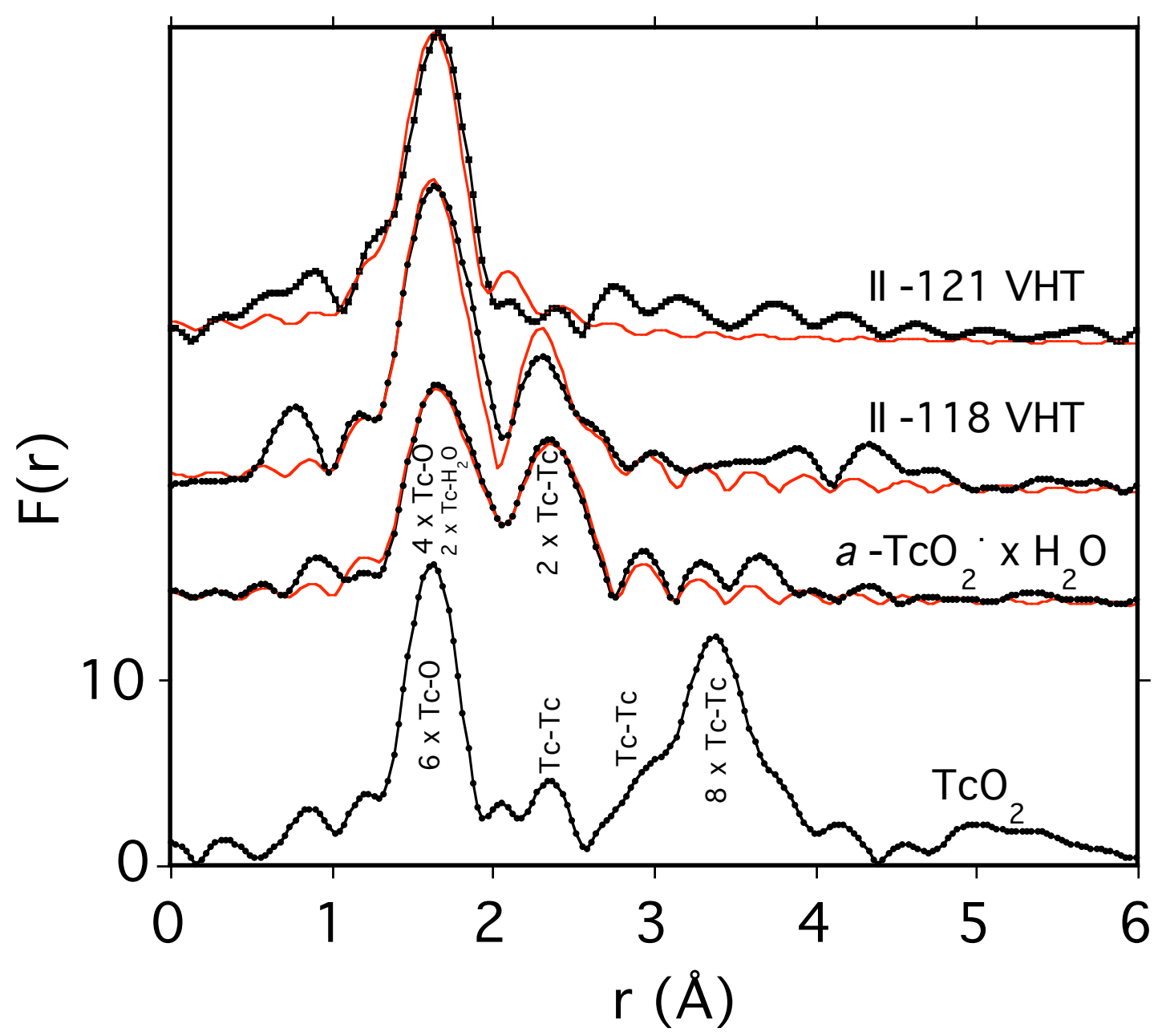

Figure 5: Tc partial RDFs (black line and points) and analysis fit (red line) for crystalline $\mathrm{TcO}_{2}, a-\mathrm{TcO}_{2} \bullet \mathrm{xH}_{2} \mathrm{O}$ and the two Tc VHT samples. Important pair correlations for $\mathrm{TcO}_{2}$ and $a-\mathrm{TcO}_{2} \bullet \mathrm{xH}_{2} \mathrm{O}$ are indicated (12). 
Table 1: Tc EXAFS Tc-O and Tc-Tc nearest-neighbor fitting results for a- $\mathrm{TcO}_{2} \bullet \mathrm{xH}_{2} \mathrm{O}$ and the two VHT samples ${ }^{\mathrm{a}}$. Uncertainties are in parentheses.

\begin{tabular}{|c|c|c|c|c|c|}
\hline Sample & r-factor ${ }^{b}$ & Correlation & $r(\AA)$ & $n$ (atoms) & $\sigma^{2}\left(\AA^{2}\right)$ \\
\hline \multirow[t]{4}{*}{$a-\mathrm{TcO}_{2} \cdot \mathrm{xH}_{2} \mathrm{O}$} & 0.007 & Tc-O: this study & $2.01(0.01)$ & $4.0(1.0)$ & $0.0033(0.0022)$ \\
\hline & & Tc-O: reference (12) & 2.02 & 3.9 & 0.0022 \\
\hline & & $\begin{array}{l}\text { Tc-O: this study } \\
\text { Tc-O: reference (12) }\end{array}$ & $\begin{array}{c}2.49(0.07) \\
2.47\end{array}$ & $\begin{array}{c}1.4(0.3) \\
1.4\end{array}$ & $\begin{array}{c}0.0065(0.0119) \\
0.0050\end{array}$ \\
\hline & & Tc-Tc: this study & $2.57(0.01)$ & $2.1(1.1)$ & $\begin{array}{c}0.0043(0.0025) \\
0.0029\end{array}$ \\
\hline \multirow[t]{2}{*}{ II-118 VHT } & 0.019 & $\mathrm{Tc}-\mathrm{O}$ & $2.00(0.01)$ & $5.8(0.8)$ & $0.0037(0.0013)$ \\
\hline & & Tc-Tc & $2.56(0.01)$ & $1.0(0.2)$ & $0.0015(0.0007)$ \\
\hline II-121 VHT & 0.021 & $\mathrm{Tc}-\mathrm{O}$ & $2.00(0.01)$ & $6.2(0.9)$ & $0.0047(0.0014)$ \\
\hline
\end{tabular}

a) All fits used: $\mathrm{s}_{0}^{2}=0.98$ and $\mathrm{E}_{0}=21,029.7 \mathrm{eV}$.

b) $\mathrm{r}$-factor $=\left(\sum\left(\mathrm{y}_{\mathrm{i}}(\text { data })-\mathrm{y}_{\mathrm{i}}(\mathrm{fit})\right)^{2} / \sum\left(\mathrm{y}_{\mathrm{i}}(\text { data })\right)^{2}\right)^{1 / 2}$.

The EXAFS fitting routines for the VHT samples used a model based on the number of major RDF peaks for each sample: two shells were fit (Tc-O and Tc-Tc) to the II-118 data, while one shell was fit (Tc-O) to the II-121 data (Table 1). The second nearest-neighbor RDF peak in the II-118 VHT data could also be due to other cations than Tc in the original glass, such as Fe and Ti. Tc(IV) has a similar ionic radius to Fe(III) and Ti(IV) and has been known to substitute for Ti(IV) in titanium compounds (17). Therefore, two other fitting routines were applied to the II-118 VHT data, where the Tc-Tc path in the original model was replaced by Tc-Fe and then Tc-Ti. Both models 
poorly fit the experimental second-shell partial RDF peak, where $n$ or $\sigma^{2}$ refined to negative values. Therefore, the short $2.56 \AA$ cation-cation second nearest-neighbor distance is best described by Tc-Tc, which is observed in both $a-\mathrm{TcO}_{2} \bullet \mathrm{xH}_{2} \mathrm{O}$ and crystalline $\mathrm{TcO}_{2}(11,12)$.

The initial fits for the II-118 VHT sample did not completely describe the RDF amplitudes between 1.5 and $2.5 \AA$ (Fig. 5). Another model was used, which added a Tc-O correlation, similar to that used for the water molecules coordinating with Tc in $a$ $\mathrm{TcO}_{2} \bullet \mathrm{xH}_{2} \mathrm{O}$; this model marginally improved the fit. This three-shell fit suggests that $\mathrm{H}_{2} \mathrm{O}$ may coordinate with some of the Tc atoms at distances near $2.45 \AA$.

The fitting results for both VHT samples (Table 1) are consistent with local environments characteristic of Tc(IV), which support the XANES findings. The Tc environments in the VHT samples are considerably different from pertechnetate environments $(9,10)$. The EXAFS data and fitting results also show that the Tc-O nearestneighbor environments in the VHT samples are different from that in $a-\mathrm{TcO}_{2} \bullet \mathrm{xH}_{2} \mathrm{O}$. Larger nearest-neighbor peak amplitudes for the two VHT samples (Fig. 5) correlate with the larger nearest-neighbor coordination numbers, and indicate somewhat regular $\mathrm{TcO}_{6}$ octahedra. Tc in the II-118 VHT sample could be within $\mathrm{Tc}_{2} \mathrm{O}_{10}$ dimers, where two $\mathrm{TcO}_{6}$ units share two oxygen atoms, similar to the proposed environment between two $\mathrm{TcO}_{6}$ units in solutions and other compounds $(12,18)$. Tc in the II-121 VHT sample is also within somewhat regular $\mathrm{TcO}_{6}$ octahedra that appear to be isolated from each other.

\section{VHT Treated Samples: Re-Containing Melter Glasses}

SEM Observations. SEM investigations of the cross-sections of both Re-containing VHT samples indicate $\mathrm{Re}_{2} \mathrm{O}_{7}$ concentration profiles (Fig. 6, Table S4) that are distinctly 
different from those measured for the Tc-containing VHT samples (Fig. 1). Both Recontaining VHT samples were not completely altered and portions of the original glass were found near the center of each sample. $\mathrm{Re}_{2} \mathrm{O}_{7}$ concentrations near the WVT-G-128B VHT sample surface are near zero, where some concentration enhancement was observed for both samples between 20 and $100 \mu \mathrm{m}$ depths. At depths greater than $375 \mu \mathrm{m}$, concentrations increase toward the unaltered glass (700 $\mu \mathrm{m}$ depth in Fig. 6) to approach the original glass concentration.
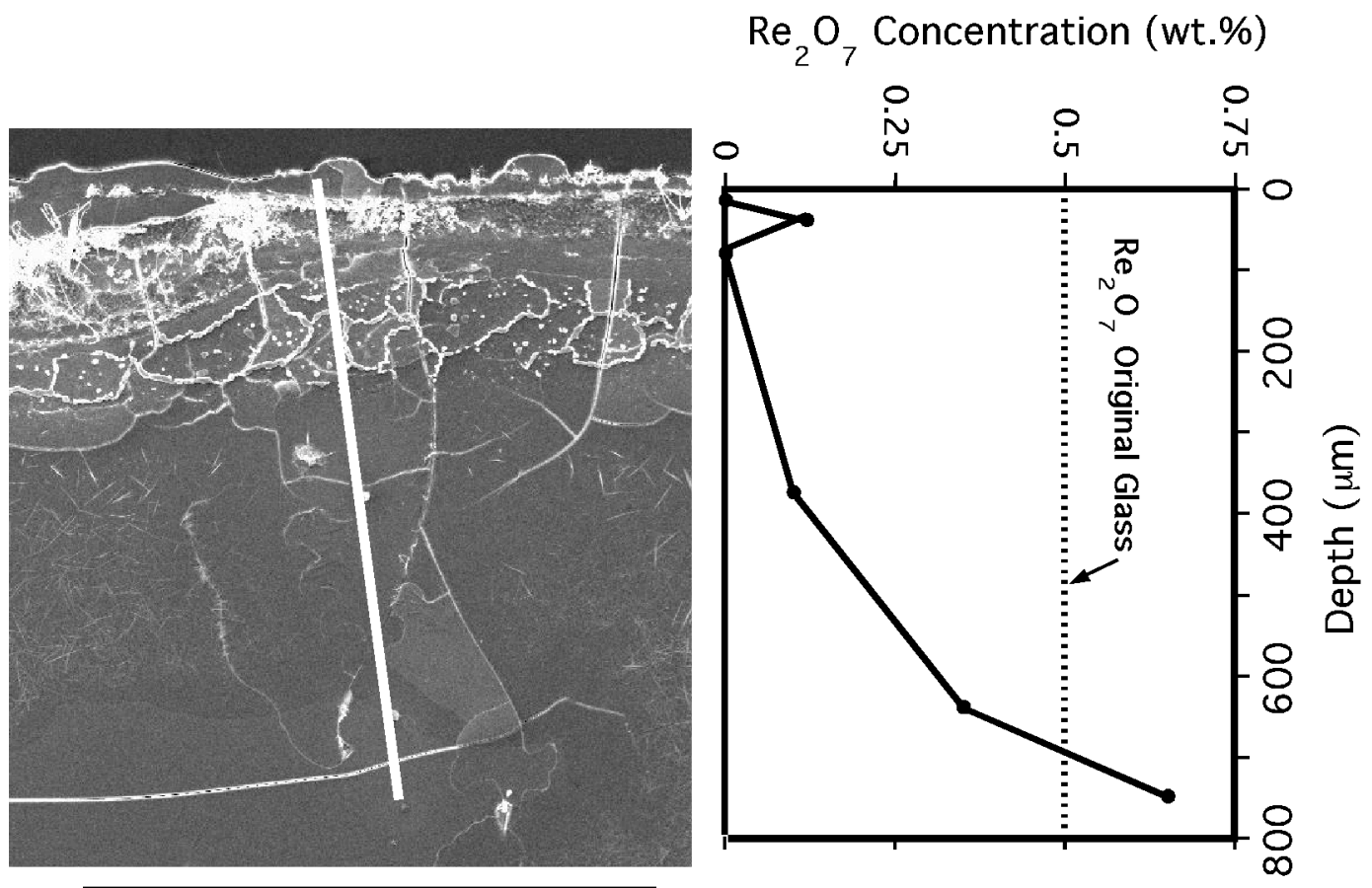

$700 \mu \mathrm{m}$

Figure 6: SEM-WDS $\operatorname{Re}_{2} \mathrm{O}_{7}$ analyses for the WVT-G-128B VHT sample cross-section. The analysis profile is the white bar in the SEM micrograph.

XAS Results. The two Re-containing melter glasses used in the VHT tests, have 100\% of all Re was perrhenate in the original glasses, as shown by XANES and EXAFS (9). XANES data for both VHT altered samples also indicate perrhenate as the sole Re 
species (Fig. 7). XANES data for both glasses and their corresponding VHT samples are nearly identical to those for $\mathrm{NH}_{4} \mathrm{ReO}_{4}(9)$.

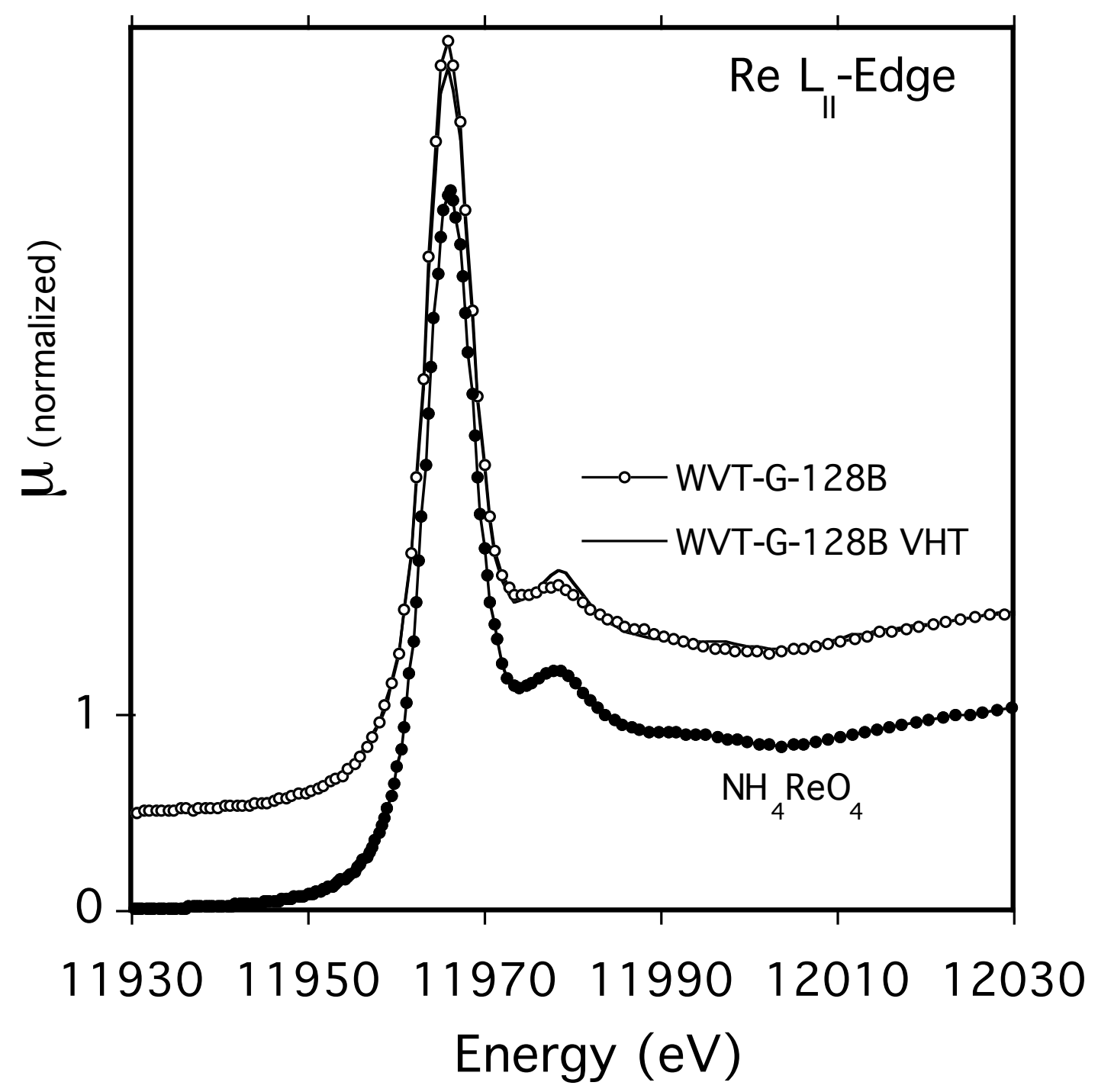

Figure 7. $\mathrm{Re} \mathrm{L}_{\mathrm{II}}$-edge $\mathrm{XANES}$ data for $\mathrm{NH}_{4} \mathrm{ReO}_{4}$ as well as the melter glass WVT-G128B before and after VHT treatment (offset for clarity). The spectra indicate 100\% perrhenate $(\operatorname{Re}(\mathrm{VII}))$ in both samples. 
Possible Tc Reduction Mechanism. The cause of the Tc reduction in the VHT environment is not well understood. However, earlier observations about Tc behavior in environments similar to that within the VHT vessel may provide some insights. Tc release was observed from glass powder in water within a heated stainless steel vessel (19), where a sudden drop of the Tc concentration in the glass was seen after 560 days; this drop was attributed to the formation of poorly soluble Tc(IV). Similar results were also obtained within depleted oxygen environments, where $\mathrm{Zn}$-amalgam was used to deliberately scavenge oxygen (20). In other studies, Tc was soluble in air at room temperature, in systems containing water, glass, $\mathrm{Tc}(\mathrm{VII})$, stainless steel, and $\mathrm{UO}_{2}$; Tc was found to be insoluble under reducing conditions created by the addition of either metallic or ferrous iron (21).

The likely explanation for the Tc reduction is oxygen loss in the VHT environment due the majority of the oxygen in the vessel being displaced by $\mathrm{Ar}$ and to corrosion of the stainless steel vessel. Signs of corrosion are typically observed on the interior walls of the VHT vessels after testing. The oxidation state of Tc is related in a simple way to the presence of oxygen; for example:

$$
4 \mathrm{x}+2 \mathrm{H}_{2} \mathrm{O}+4 \mathrm{NaTcO}_{4}=4 \mathrm{TcO}_{2} \cdot \mathrm{xH}_{2} \mathrm{O}+4 \mathrm{NaOH}+3 \mathrm{O}_{2}
$$

Under oxidizing conditions the above equation is driven to the left, where $\mathrm{TcO}_{2} \bullet \mathrm{xH}_{2} \mathrm{O}$ is rapidly oxidized to $\mathrm{Tc}(\mathrm{VII})$; under reducing conditions, the equation is driven to the right, where $\mathrm{NaTcO}_{4}$ is rapidly reduced to Tc(IV). Therefore, if the system becomes oxygen depleted, then $\mathrm{Tc}(\mathrm{VII})$ will be reduced to Tc(IV). In addition, further oxygen depletion in the VHT environment may be caused by oxidation of the protective $\mathrm{Cr}_{2} \mathrm{O}_{3}$ layer on the stainless steel vessel, which has been observed in corrosive environments (22). Further work is needed to test this hypothesis.

The observation that Re remains oxidized while Tc is reduced can be explained by the redox behavior of these metals in the presence of $\mathrm{Fe}$, the most abundant redox- 
active metal in the VHT system. The $\mathrm{Fe}$ (II)/Fe(III) equilibrium will determine the oxygen fugacity in the VHT vessel, and therefore, the redox state of the other metals. The results of this study are consistent with $\mathrm{Fe}(\mathrm{II}) / \mathrm{Fe}$ (III) ratios of 0.004 to 5.4....NEED MORE...

Overview of Results. The XAS and SEM information obtained for the original Tccontaining glasses and corresponding VHT samples shows that the alteration processes that took place, significantly changed the Tc valence and distribution within each sample. XAS data show that despite having different initial Tc distributions in the two original waste glasses, all Tc was reduced to Tc(IV) as both glasses were altered under VHT conditions. Both XAS and SEM show that Tc concentrated near the surface of the VHT sample. Since there is no clear evidence from SEM or XRD of Tc-containing crystals in either VHT altered sample, amorphous Tc-silicate gel-like phases may have formed near the sample surface.

Re behaved quite differently from Tc in response to VHT alteration. Re speciation remained unchanged from the original glass to the altered samples, where most, if not all Re is perrhenate. $\operatorname{Re}_{2} \mathrm{O}_{7}$ concentrations increase from small values near the VHT sample surface to values near that for the original glass toward the sample center. This behavior indicates that some Re was lost from the outer portions of the VHT coupon, which is not consistent with Tc behavior. Re is not a good surrogate for Tc under VHT conditions, which reinforces the earlier findings concerning different $\mathrm{Tc}$ and Re behavior as these elements are incorporated into waste glasses (9).

Differences between Tc and Re valence behavior in the VHT environment can be related to the different redox potentials for these two elements (9). Since Fe dominates the redox sensitive cation content in the glass chemistries studied, the $\mathrm{Fe}(\mathrm{III}) / \mathrm{Fe}$ (II) redox couple can maintain oxygen fugacities at levels where Tc(IV) and Re(VII) coexist.

The VHT results presented are a first evaluation of Tc and Re behavior within this environment. One must consider that the VHT may not be a realistic model of what a 
glass may encounter over time in a waste repository; the following statements need to be be considered with the above short-comings in mind. From the perspective of Tc immobilization, reduction of Tc can be regarded as desirable, since Tc(IV) is less mobile in the environment than Tc(VII) within pertechnetate. However, Tc was also found to migrate and concentrate toward the surface of the waste-form material as alteration takes place, which is clearly undesirable. Furthermore, it is possible that over long time periods, Tc(IV) near the surface of an altered glass in air may oxidize to form the mobile pertechnetate species. Further experiments are necessary to determine whether such trends are replicated in conditions more consistent with a long-term environment in a nuclear waste depository.

ACKNOWLEDGMENT. This work was supported in part by grant DE-FG0204ER63814 to Catholic University from the Department of Energy's Environmental Management Science Program (EMSP). Part of this work was performed at Lawrence Berkeley National Laboratory and was supported by the Director, Office of Science, Office of Biological and Environmental Research of the U.S. Department of Energy under Contract No.: DE-AC02-05CH11231. Portions of this research were carried out at the Stanford Synchrotron Radiation Laboratory, a national user facility operated by Stanford University on behalf of the U.S. Department of Energy, Office of Basic Energy Sciences. The SSRL Structural Molecular Biology Program is supported by the Department of Energy, Office of Biological and Environmental Research, and by the National Institutes of Health, National Center for Research Resources, Biomedical Technology Program.

SUPPORTING INFORMATION AVAILABLE: Further details about the experimental procedures and XAS analysis are available at http://pubs.acs.org. 


\section{REFERENCES}

(1) Yoshihara, K. "Technetium in the environment," Topics in current chemistry, 1996, $176,18-34$.

(2) Lieser, K.H.; Bauscher, C. "Technetium in the hydrosphere and geosphere 1. Chemistry of technetium and iron in natural waters and influence of the redox potential on the sorption of technetium" Radiochimica Acta, 1987, 42, 205-213.

(3) Ewing, R.C.; "Natural glasses: Analogues for radioactive waste forms" Scientific basis for nuclear waste management. G. J. McCarthy (ed.) New York, NY; Plenum Press (1979) pp 57-68.

(4) Buechele, A.C.; Lai, S.-T.; Pegg, I.L. Alteration Phases on High Sodium Waste Glasses after Short- and Long-Term Hydration. Ceramic Transactions, 2000, 107, 251259.

(5) Buechele, A.C.; Lofaj, F.; Mooers, C.; Pegg, I.L. Analysis of Layer Structures Formed during Vapor Hydration Testing of High-Sodium Waste Glasses. Ceramic Transactions, 2002 132, 301-309.

(6) Lu, X.; Perez-Cardenas, F.; Gan, H.; Buechele, A.C.; Pegg, I.L. Kinetics of Alteration in Vapor Phase Hydration Tests on High Sodium Waste Glass. Ceramic Transactions, 2002, 132, 311-322.

(7) Schatz, T.; Buechele, A.C.; Mooers, C.T.F.; Wysoczanski, R.; Pegg, I.L. Vapor Phase Hydration of Glasses in $\mathrm{H}_{2} \mathrm{O}$ and $\mathrm{D}_{2} \mathrm{O}$. Ceramic Transactions, 2003, 143, 253-261.

(8) Buechele, A.C.; Lofaj, F.; Muller, I.S.; Mooers, C.T.F.; Pegg, I.L. Composition Effects on the Vapor Hydration of Waste Glasses Ceramic Transactions, 2004, 155, 289296.

(9) Lukens, W.W.; McKeown, D.A.; Buechele, A.C.; Muller, I.S.; Shuh, D.K.; Pegg, I.L. Incongruent behavior of technetium and rhenium in borosilicate waste glass as determined by X-ray absorption spectroscopy. submitted to Chem. Materials.

(10) Allen, P.G.; Siemering, G.S.; Shuh, D.K.; Bucher, J.J.; Edelstein, N.M.; Langton, C.A.; Clark, S.B.; Reich, T.; Denecke, M.A. Technetium speciation in cement waste forms determined by X-ray absorption fine structure spectroscopy. Radiochim. Acta, 1997, 76, 77-86.

(11) Almahamid, I.; Bryan, J.C.; Bucher, J.J.; Burrell, A.K.; Edelstein, N.M.; Hudson, E.A.; Kaltsoyannis, N.; Lukens, W.W.; Shuh, D.K.; Nitsche, H.; Reich, T. Electronic and structural investigations of Tcchnetium compounds by X-ray absorption spectroscopy. Inorg. Chem., 1995, 34, 193-198. 
(12) Lukens, W.W.; Bucher, J.J.; Edelstein, N.M.; Shuh, D.K. Products of pertechnetate radiolysis in highly alkaline solution: structure of $\mathrm{TcO}_{2} \bullet \mathrm{xH}_{2} \mathrm{O}$. Environ. Sci. Technol., 2002, 36, 1124-1129.

(13) Matlack, K.S.; Kot, W.K.; Pegg, I.L. Tc-Cs Volatility in DM100 Tests Using HLW AZ-102 and LAW Sub-Envelope A1 Simulants, Report VSL-04R4710-1, Vitreous State Laboratory, The Catholic University of America, Washington, DC, July, 2004.

(14) Sayers, D.E.; Bunker, B.A. in: X-ray Absorption Principles, Applications, Techniques of EXAFS, SEXAFS, and XANES, ed. D.C. Kroningsberger, R. Prins (Wiley, New York, 1988), Ch. 6, p. 211.

(15) Zabinsky, S.I.; Rehr, J.J.; Ankudinov, A.; Albers, R.C.; Eller, M.J. Multiple scattering calculations of X-ray absorption spectra. Phys. Rev. 1995, B 52, 2995-3009.

(16) Newville, M.; Ravel, B.; Haskel, D.; Stern, E.A.; and Yacoby, Y. Analysis of multiple-scattering XAFS data using theoretical standards. Physica B 1995 208-209, 154156.

(17) Muller, O.; White, W.B.; Roy, R. Crystal chemistry of some technetium containing oxides, J. Inorg. Nucl. Chem., 1964, 26, 2075-2086.

(18) Alberto, R.; Anderegg, G.; Albinati, A. Synthesis and x-ray structure of a new $\mathrm{Tc}(\mathrm{IV})$ oxalato complex: $\mathrm{K}_{4}\left[\left(\mathrm{C}_{2} \mathrm{O}_{4}\right)_{2} \mathrm{Tc}(\mu-\mathrm{O})_{2} \mathrm{Tc}\left(\mathrm{C}_{2} \mathrm{O}_{4}\right)\right] \cdot 3 \mathrm{H}_{2} \mathrm{O}$ Inorg. Chim. Acta 1990, $178,125$.

(19) Ebert, W.L.; Wolf, S.F.; Bates, J.K. The release of technetium from defense waste processing facility glasses, Mat. Res. Soc. Symp. Proc., 1996, 412, 221-227.

(20) Bibler, N.E. and Jurgensen, A.R. Leaching of Tc-99 from SRP Glass in Simulated Tuff and Salt Groundwaters, Mat. Res. Soc. Symp. Proc., 1988, 112, 585-593.

(21) Kunze, S; Neck, V.; Gompper, K.; Fanghänel, T. Studies on the immobilization of Technetium under near field conditions, Radiochimica Acta, 1996, 74, 159-163.

(22) Kritzer, P. Corrosion in high-temperature and supercritical water and aqueous solutions: a review. J. Supercritical Fluids, 2004, 29, 1-29. 


\section{Brief:}

Technetium and rhenium in borosilicate waste glasses subjected to Vapor Hydration Tests behave quite differently with respect to ion mobility, valence, and local structural changes during alteration. 